\title{
Penerapan Alat Pembuatan Kotak Kardus Yang Ergonomis Berdasarkan Ukuran Anthropometri
}

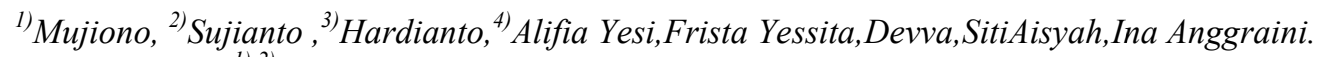 \\ ${ }^{1), 2)}$ Dosen Teknik Industri, Institut Teknologi Nasional Malang \\ ${ }^{3)}$ Dosen Teknik Lingkungan, Institut Teknologi Nasional Malang \\ ${ }^{4)}$ Mahasiswa Teknik Industri D.III, Institut Teknologi Nasional Malang \\ E-mail :mujiono1064@gmail.com
}

\begin{abstract}
Tim abdimas melakukan pertemuan untuk membahas pelaksanaan yang akan dilakukan untuk melakukan survey kelokasi mitra yang akan dijadikan obyek untuk abdimas. Tujuan dari survey ini untuk mengetahui apa saja yang dibutuhkan oleh mitra, hasilnya informasi yang diperoleh dari mitra adalah sering terjadinya kecelakaan, rusak, ukuran tidak bisa sama dalam melakukan pembuatan kotak kardus karena alat yang dipergunakan masih sangat sederhana yaitu cutter, pisau potong tekan atau pisau silet, mal kotak kardus dan mal kotak kardus dibedakan jadi dua sisi, sisi kanan dan sisi kiri kemudian kedua sisi tersebut dilem pakai lem kayu.

Melihat kondisi yang terjadi pada mitra tersebut maka tim abdimas akan mengembangkan/inovasi perancangan alat pembuatan kotak kardos dengan menggunakan alat dengan desain ergonomis. Desain ergonomis yang dimaksud adalah desain alat yang menghasilkan suatu sistem kerja dengan menggunakan ukuran anthropometri., dengan tujuan agar supaya mitra lebih mudah untuk mengunakan alat tersebut dan menghidari sering terjadinya kecelakaan, kerusakan, sehingga pekerjaan mitra lebih effektif,effisien dapat menghemat waktu sehingga hasil jauh lebih baik dan produktif.

Melihat masalah yang dihadapi mitra maka tim abdimas membuatkan alat dengan menggunakan data anthropometri dengan ukuran alat tinggi $105 \mathrm{~cm}$, lebar $77 \mathrm{~cm}$ dan panjang $85 \mathrm{~cm}$, sehingga dapat meningkatan produktifitas dari 2.4 kodi per jam menjadi 9.6 kodi per jam.
\end{abstract}

Keywords : perancangan alat,ergonomis, produktif

\section{Pendahuluan}

Lokasi abdimas ini berada didaerah Purwasari Kabupaten Pasuruan dimana di daerah tersebut banyak bermunculan produk- produk baru yang tentunya memerlukan wadah atau pembungkus yang pada umumnya menggunakan kotak kardus.

Dari sekian banyak produk dari industri kecil rumahan semua bergantung pada wadah atau pembungkus salah satunya adalah kotak kardus untuk wadah tersebut, namun pada saat ini industri kecil pembuatan kotak kardus masih menggunakan cara/alat manual dalam pembuatannya yaitu menggunakan cutter, pisau potong tekan atau pisau silet, mal kotak kardus dan mal kotak kardus dibedakan jadi dua sisi, sisi kanan dan sisi kiri kemudian kedua sisi tersebut dilem pakai lem kayu dan pembuatan kotak kardus ini dengan posisi berdiri dan agak membungkuk (gb.1.), sehingga untuk memenuhi kebutuhan konsumen memerlukan banyak waktu dan tenaga, selain itu ukuranya tidak seragam, bagian kotak kardus tersebut ada yang terpotong dan tidak terpotong, sehingga terjadi kerusakan yang mengakibatkan keterlambatan permintaan konsumen.

Berdasarkan kekurangan- kekurangan diatas maka Tim Abdimas perlu membuatkan alat kerja pembuatan kotak kardus yang ergonomis. Agar mitra lebih produktif dalam menjalani usahanya.

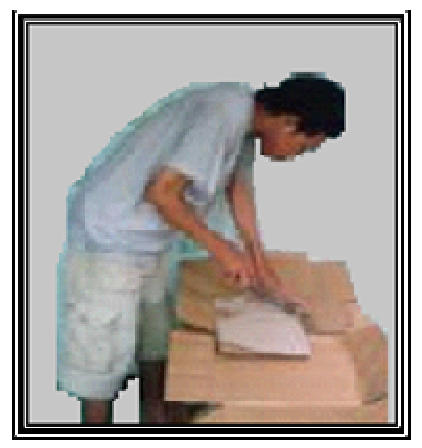

Fig. 1. Gambar 1, Cara kerja alat manual 


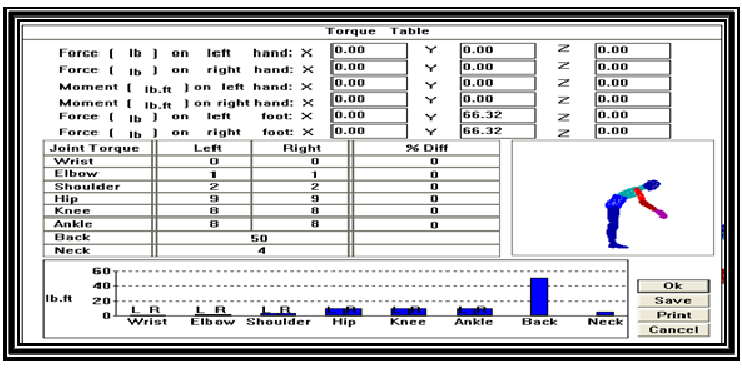

Fig. 2. Gambar 2, Beban torsi alat manual

\section{METODE KEGIATAN PENGABDIAN KEPADA MASYARAKAT.}

1. Survey data lapangan

Dilakukan untuk mencari informasi tentang kondisi alat pembuat kotak kardus dengantujuan untuk mengetahui permasalahan yang ada dalam proses pembuatan kotak kardus

2. Melakukan pengumpulan data diperlukan sebagaipenunjang antara lain:

a) Data alat pembuat kotak kardus yang sedang dipergunakan

b) Proses pembuatan kotakkardus

c) Waktu yang diperlukan dalam pembuatan kotak kardus

3. Pengolahan Data

Dilakukan untuk mengetahui permasalalahan yang ada untuk menentukan ukuran kotak kardus serta sistem kerja pembuatan kotak kardus sesuai dengan pengrajin kotak kardus.

4. Pemecahan masalah

Survey ke lokasi pengabdian, perumusan masalah,pengumpulan data, pengolahan data,perbandingan alatmanual dengan alat hasilperancangan.

5. Antropometri yang dipergunakan.

\begin{tabular}{|c|c|r|l|}
\hline $\begin{array}{c}\text { Jenis data/ } \\
\text { Percentil }\end{array}$ & $5 \%$ & $50 \%$ & $95 \%$ \\
\hline Tinggi siku & $105 \mathrm{~cm}$ & & \\
\hline $\begin{array}{c}\text { Jangkauan } \\
\text { samping }\end{array}$ & & $85 \mathrm{~cm}$ & \\
\hline $\begin{array}{c}\text { Jangkauan } \\
\text { depan }\end{array}$ & & $77 \mathrm{c}$ & \\
\hline
\end{tabular}

6. Pembahasan hasil rancangan

Pengajin kotak kardus yang berada di Purwosari Pasuruan ini memproduk berbagai ukuran kotak kardus, secara umum masih menggunakan alat manual

7. Tahapan Pembuatan kotak kardus

Proses pembuatan kotak kardus di UD.Utomo ini awalnya hanya membuat kotak kardus untuk tempat sepatu dengan bahan baku kardus bekas.Akan tetapi sekarang sudah bisamemproduksi kotak kardus dengan berbagai ukuran dan bentuk dengan bahan baku karton seperti proses produksi dibawah : 


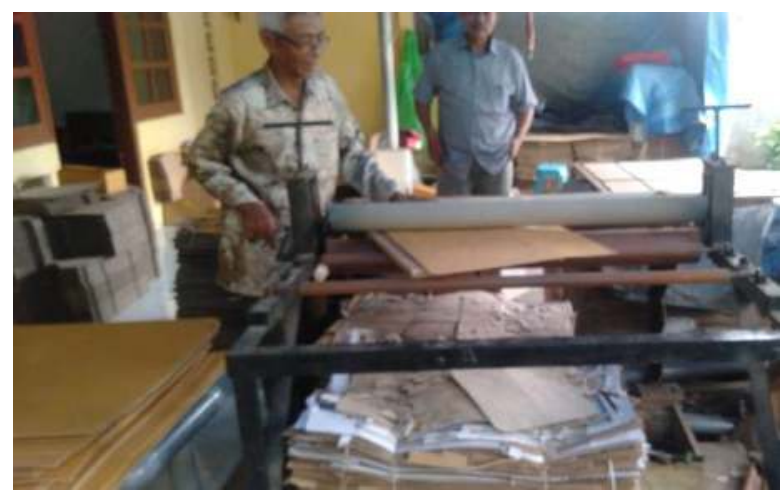

Fig. 3. Gambar : IPTEK

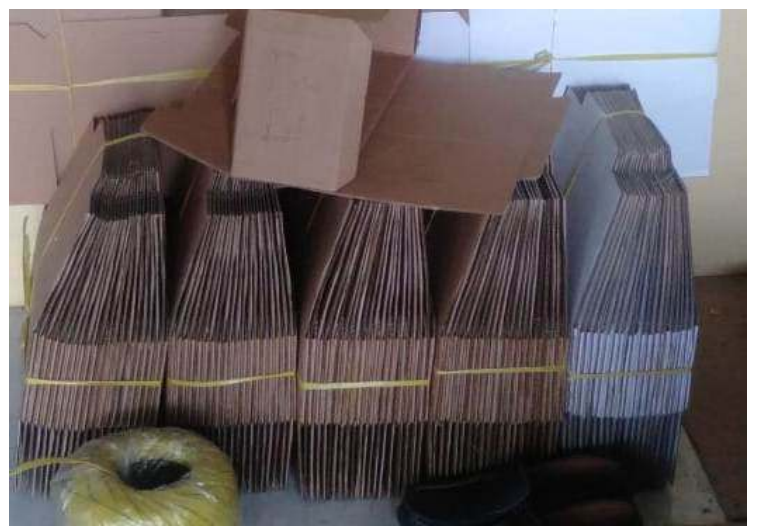

Fig. 4. Gambar : IPTEK

\section{DESKRIPSI ALAT}

Alat ini didesain berdasarkan ukuran anthropometri operator dengan tinggi alat $105 \mathrm{~cm}$, lebar alat $77 \mathrm{~cm}$ dan panjang alat $85 \mathrm{~cm}$, dengan produktifitas $9.6 \mathrm{kodi} / \mathrm{jam}$

\section{SPESIFIKASI ALAT}

kerangka besi siku dengan ukuran $5 \mathrm{~cm}$ dan tebal $0,3 \mathrm{~cm}$. Rol Penjepit : dua buah rol, panjang sama yaitu 77 $\mathrm{cm}$.diameternya adalah $4 \mathrm{~cm}$. Pisau mal : pisau yang terbuat dari plat baja dan diberi cover atau suport Hardboard panjang $50 \mathrm{~cm}$, lebar $40 \mathrm{~cm}$ dan tebal Hardboard $2 \mathrm{~cm}$, Engkol : dari pipa besi dengan diameter $3 \mathrm{~cm}$ dan panjang $28 \mathrm{~cm}$ dengan tekukan atas untuk menyambung ke rol penjepit dengan panjang $10 \mathrm{~cm}$, Rol Conveyor : Terbuat dari pipa besi dengan panjang sama dengan rol penjepit diameter $3 \mathrm{~cm}$ dan panjang $77 \mathrm{~cm}$

\section{WAKTU PEMBUATAN DENGAN MENGGUNAKAN MANUAL DIPEROLEH DATA :}

Waktu siklus $(\mathrm{Ws})=20.40$ menit

Performance $(\mathrm{P})=1.11$

Allowance $\%=9 \%$

Diperoleh waktu Norman(Wn)

$W_{n}=W_{s} \times P=20.40 \times 1.11$

$W_{n}=22.6$ menit $/$ kodi

$W_{b}=W_{n} \times \frac{100 \%}{100 \%-\text { allownce }(\%)}$

$W_{b}=22.6 \times \frac{100 \%}{100 \%-9 \%}=24.8$ menit $/$ kodi 


$$
\begin{aligned}
O_{s} & =\frac{1}{W_{b}}=\frac{1}{24.8}=0.04 \mathrm{kodi} / \mathrm{menit} \\
O_{s} & =2.4 \mathrm{kodi} / \mathrm{jam}
\end{aligned}
$$

\section{WAKTU PEMBUATAN DENGAN MENGGUNAKAN SARANA KERJA BARU}

Waktu siklus $(\mathrm{Ws})=5.15$ menit

Performance $(\mathrm{P})=1.11$

Allowance $\%=9 \%$

Diperoleh waktu Norman(Wn)

$W_{n}=W_{s} \times P=5.15 \times 1.11$.

$W_{n}=5.7$ menit / kodi

$W_{b}=W_{n} \times \frac{100 \%}{100 \%-\text { allownce }(\%)}$

$W_{b}=5.7 \times \frac{100 \%}{100 \%-9}=6.26$ menit $/$ kodi

$O_{s}=\frac{1}{W_{b}}=\frac{1}{6.26}=0.16$ kodi $/$ menit

$O_{s}=9.6$ kodi / jam

\section{KESIMPULAN}

Dari hasil pengabdian kepada masyarakat yang dilaksanakan dapat disimpulkan :

1. Desain alat menggunakan ukuran anthropometri dengan tinggi alat $105 \mathrm{~cm}$, lebar alat $77 \mathrm{~cm}$ dan panjang alat $85 \mathrm{~cm}$.

2. Dari hasil perhitungan menggunakan alat lama dapat memproduksi 2.4 kodi per jam, sedangkan sarana alat baru dapat meningkatkan menjadi 9.6 kodi per jam

3. Menggunakan alat baru jauh lebih effisien waktu dan proses produksi lebih cepat, aman dan nyaman.

\section{DAFTAR PUSTAKA}

[1] Akao, Yoji. 1998. Quality Function Deployment: Intergrating Customer Requirement into Product Design. Oregon: Productivity Press.

[2] Betts John E, 1983, Element of Applied Physics, reston, USA

[3] Yarns. Technology,Structure and Applications.John Wiley \& Sons.New York

[4] Nurmianto Eko, 2004, Ergonomi Konsep Dasar dan Aplikasinya, Edisi ke-2, Surabaya

[5] Nigel Cross, 1996, Engineering Design Methods (Strategies For Product Design)Second Edition.

[6] Sritomo W, 2000, Ergonomi Studi Gerak dan Waktu, Guna widya. 